\title{
Evaluation of Autoantibodies in patients with Systemic Sclerosis
}

\author{
Marzieh Asgari $^{1}$, Hoda Kavosi ${ }^{1,2}$, Samaneh Soltani ${ }^{1}$, Amir Ashraf-ganjouei ${ }^{1}$, Ali Javinani ${ }^{1}$, Elham Farhadi ${ }^{1,2}$, Ashkan \\ Asadollahbaik ${ }^{1}$, Nooshin Ahmadzadeh ${ }^{1}$, Shiva Poursani ${ }^{1}$, Ahmadreza Jamshidi ${ }^{1}$, Mahdi Mahmoudi, ${ }^{12^{*}}$, \\ Farhad Gharibdoost ${ }^{1 *}$
}

\section{${ }^{1}$ Rheumatology Research Center, Tehran University of Medical Sciences, Tehran, Iran. ${ }^{2}$ Inflammation Research Center, Tehran University of Medical Sciences, Tehran, Iran.}

\begin{abstract}
Systemic sclerosis is an autoimmune disease clinically characterized by vascular and immune dysfunction, leading to fibrosis that can damage multiple organs. The presence of non-overlapping SSc-associated autoantibodies best presents the autoimmune nature of systemic sclerosis. The primary purpose of this study was to investigate the autoantibody profile in Iranian patients with systemic sclerosis. Sera from 481 patients with systemic sclerosis were collected from 2013 to 2016 . Levels of anti-nuclear antibodies (ANA) were quantitatively detected using the indirect immunofluorescence (IIF) method, and levels of specific autoantibodies including anti-topoisomerase I antibody (ATA), anti-centromere antibody (ACA) and anti RNA polymerase III antibody (anti-RNAP III) were determined qualitatively using the enzyme-linked immunosorbent assay (ELISA) technique. Among all patients evaluated, a predominance of females $(86.7 \%)$ was found, and $434(90.2 \%)$ patients showed positive ANA results by IIF. ANA was detected in $87.3 \%$ and $92.0 \%$ of limited cutaneous systemic sclerosis (lcSSc) and diffuse cutaneous systemic sclerosis $(\mathrm{dcSSc})$ patients, respectively, which was not significantly different. The frequency of anti-RNAP III, ACA, and ATA was $5.19 \%, 6.09 \%$, and $72.3 \%$, respectively. Furthermore, anti-RNAP III, ATA, and ANA levels were correlated with $\mathrm{dcSSc}$, whereas ACA levels were correlated with lcSSc. It was confirmed that ATA expression is significantly higher in dcSSc patients. This study had a lower frequency of ACA (6.09\%) than most previous cohorts. The results demonstrated that the clinical subtype of systemic sclerosis may correlate positively with the presence of specific autoantibodies.
\end{abstract}

Keywords: Systemic Sclerosis; autoantibody; anti-nuclear antibody; anti-topoisomerase I antibody; anti-centromere antibody; anti RNA polymerase III antibody

\section{Introduction}

Systemic sclerosis (SSc, scleroderma) is a multisystemic chronic autoimmune connective tissue disorder characterized by extensive fibrosis, vascular abnormalities, and immune dysfunction [1]. The exact etiopathogenesis of $\mathrm{SSc}$ remains unknown, although in genetically susceptible individuals, environamental triggers and dysregulated epigenetic changes contribute to the development of SSc [2]. Systemic sclerosis is more prevalent in black people; however, it is found in all racial groups and all geographic regions [3].

A serological hallmark of systemic sclerosis is the presence of serum autoantibodies against various intracellular antigens. Autoantibodies have been observed at first diagnosis in more than $95 \%$ of patients affected with systemic sclerosis [4]. Each of the autoantibodies is beneficial in the diagnosis of affected patients. Different autoantibodies have been associated with different disease subtypes and with differences in disease severity, including the extent of skin involvement, internal organ manifestations, as well as determining the prognosis [5]. All of these antibodies are directed against structures within the nucleus of the cell and, thus, are ANAs. Some ANAs, including ACA, ATA/anti-Scl-70 antibody, antifibrillarin/anti-U3-ribonucleoprotein (AFA), anti-PM/Scl antibody, anti-Th/To antibody, and anti-RNAP III are found in the sera of systemic sclerosis patients [4].

Personal non-commercial use only. Rheumatology Research Journal. Copyright (C) 2020. All rights reserved

*Corresponding Author: Mahdi Mahmoudi, Ph.D., Rheumatology Research Center (RRC), Shariati Hospital, Tehran University of Medical Sciences (TUMS), Tehran, Iran. PO-Box: 1411713137, E-mail: mahmoudim@tums.ac.ir, Telefax: +98-218-822-0067.

And Farhad Gharibdoost, Rheumatology Research Center (RRC), Shariati Hospital, Tehran University of Medical Sciences (TUMS), Tehran, Iran. PO-Box: 1411713137, E-mail: gharibdoost@sina.tums.ac.ir, Telefax: +98-218-8220067.

Received: 31 October 2019; Accepted: 11 November 2019 
The subgrouping of systemic sclerosis patients based on their serum ANA in the early stages of the disease may be practical for assessing the risk and nature of organ involvement and estimating survival in these patients [6]. Each subgroup is associated with a different type of autoantibody [7].

The presence of ACA is most often associated with a variant of SSc, CREST syndrome (calcinosis, Raynaud's phenomenon, esophageal dysmotility, sclerodactyly, and telangiectasia) [8], and has a better prognosis than ATApositive SSc patients [7].

ACAs are mostly found in patients with lcSSc [9, 10] and pulmonary hypertension [7], whereas the presence of ATA is associated with dcSSc, pulmonary fibrosis, musculoskeletal and cardiac involvement, and proteinuria; thus, it represents a poorer prognosis and higher rate of mortality [11-14].

The presence of both anti-RNAP I and III and a higher prevalence of renal crisis but not pulmonary fibrosis are seen with dcSSc $[15,16]$. Thus, the survival rate in patients with anti-RNAP is better than in patients with ATA [4, 17].

It has been documented that purified human ATAs impede relaxation of super helical DNA [18], anti-RNAP I /III autoantibodies inhibit RNA transcription [19], and ACAs disrupt mitosis [20, 21]. However, how these autoantibodies bind to the intracellular antigen resulting in cellular damage is not clear [5]. Henault et al. demonstrated that by binding to the surface of dermal fibroblast cell lines, topo I provides a binding site for anti-topo I and stimulates adhesion and activation of monocytes in vitro [22].

The current study assessed the prevalence of ANA, ATA, ACA, and anti-RNAP III among Iranian systemic sclerosis patients and investigated their prevalence separately in patients with dcSSc and lcSSc.

\section{Materials and Methods}

\section{Patients}

The study population comprised 481 systemic sclerosis patients from the rheumatology clinic of Shariati Hospital, Tehran, Iran, and the Iran Rheumatism Center (IRC) from 2013 to 2016. All of the cases fulfilled the American College of Rheumatology (ACR) 2013 criteria [23], and clinical data was available for all cases. The patients were categorized into dcSSc and lcSSc according to the 2013 classification criteria for SSc [23]. Written informed consent was obtained from all participants, and ethical approval for this study was obtained from Tehran University of Medical Sciences (TUMS).

Whole blood samples from each patient were collected in test tubes, and the sera were separated by centrifugation. Aliquots of sera were stored at $-70^{\circ} \mathrm{C}$ until used.

Indirect immunofluorescence (IIF) method for detection of ANA

The ANAs were quantitatively detected using the indirect immunofluorescence method via mosaic HEp-20-
10 cells and primate liver cells (EUROIMMUNE, Medizinische Labordiagnostika AG, Germany). Sera were diluted with phosphate buffered saline (PBS) at a ratio of $1 / 160$ and $1 / 640$. Twenty-four microliters of each serum sample was added to each well; then the chambers were capped and incubated for 30 minutes at room temperature (RT). Each slide was washed quickly two times with PBS. The slides were located again in the humidifier chamber, subjected to appropriate diluted goat anti-human IgG fluorescein isothiocyanate (FITC) conjugated antibody, and further incubated for 30 minutes. Subsequently, the slides were rinsed thrice with PBS for 5 minutes each. Completely blotted slides were then overlaid with a coverslip and positioned on the slide tray. The slides were stored at $4{ }^{\circ} \mathrm{C}$ until visualized using a Zeiss fluorescence microscope.

Enzyme-linked immunosorbent assay (ELISA) for detection of ATA, ACA, and anti-RNAP III

The ATA and ACA of IgG class in sera were detected using an ELISA kit (Euroimmune, Medizinische Labordiagnostika AG, Germany), and the anti-RNAP III was also determined qualitatively by an ELISA kit (Cusbio, China) according to the manufacturer's protocols.

\section{Statistical Analysis}

Statistical analyses were performed using statistical package SPSS version 22 (SPSS Inc., Chicago IL, USA), and $p$ value $<0.05$ was considered to be statistically significant.

The Benjamini and Hochberg method was used to control for false discovery rate in multiple comparisons [24].

\section{Results}

\section{Demographic data and disease classification.}

The demographic features of the participants are shown in Table 1. According to the data on accessible cases, 417 $(86.7 \%)$ were women, and $64(13.3 \%)$ were men. The female-to-male ratio was $6.5: 1$, the mean age was $43.8 \pm$ 11.5 years, and the mean disease duration was $10.5 \pm 6.5$ years. Among all participants, $181(37.6 \%)$ were classified as lcSSc, and $300(62.4 \%)$ were classified as dcSSc. Among those with lcSSc, 165 (91.2\%) were female, and 16 $(8.8 \%)$ were male, and of dcSSc patients, $252(84 \%)$ and $48(16 \%)$ were female and male, respectively.

The level of non-specific and specific systemic sclerosis-relevant autoantibodies

The frequency rates of autoantibodies detected in these patients are shown in Table 2. Among all patients, 434 $(90.2 \%)$ were ANA positive and the remaining 47 (9.7\%) were ANA negative (Table 3). Overall, ANA was detected in $158(87.3 \%)$ and $276(92.0 \%)$ of $1 \mathrm{cSSc}$ and dcSSc patients, respectively, which was not significantly different $(p$ Value $=0.092)$. 
Table 1. Demographic feature of the SSc patients.

\begin{tabular}{cccc}
\hline Demographic Variable & \multicolumn{3}{c}{ Number (Frequency) - Mean \pm SD } \\
\hline & $1 \mathrm{cSSc}$ & $\mathrm{dcSSc}$ & Total \\
$\mathrm{N}(\%)$ & $\mathrm{N}(\%)$ & $\mathrm{N}(\%)$ & $\mathrm{N}(\%)$ \\
Gender :Male & $181(37.6)$ & $300(62.4)$ & 481 \\
Gender :Female & $16(8.8)$ & $48(16.0)$ & $64(13.3)$ \\
Age (year) & $165(91.2)$ & $252(84.0)$ & $417(86.7)$ \\
Disease duration (year) & $45.6 \pm 11.4$ & $42.7 \pm 11.5$ & $43.8 \pm 11.5$ \\
\hline
\end{tabular}

Abbreviations: lcSSc, limited cutaneous Systemic sclerosis; dcSSc, diffuse cutaneous Systemic sclerosis; SD, Standard deviation

Table 2. The prevalence of the autoantibodies in SSc patients.

\begin{tabular}{cccccc}
\hline & $\begin{array}{c}\text { IcSSc } \\
\text { N }(\%)\end{array}$ & $\begin{array}{c}\text { dcSSc } \\
\text { N }(\%)\end{array}$ & P value & P value $^{\text {adj }}$ & OR (CI 95\%) \\
\hline Anti-RNAP III & $5(2.8)$ & $20(6.7)$ & 0.062 & 0.077 & $2.514(0.927-6.821)$ \\
ACA & $16(8.8)$ & $13(4.3)$ & 0.044 & 0.073 & $0.467(0.219-0.995)$ \\
ATA & $98(54.1)$ & $250(83.3)$ & $<0.001$ & $<0.001$ & $4.235(2.778-6.455)$ \\
ANA & $158(87.3)$ & $276(92.0)$ & 0.092 & 0.092 & $1.674(0.915-3.064$ \\
Seronegative & $7(3.9)$ & $2(0.7)$ & 0.012 & 0.03 & $0.167(0.034-0.812)$ \\
\hline
\end{tabular}

Abbreviations: lcSSc, limited cutaneous Systemic sclerosis; dcSSc, diffuse cutaneous Systemic sclerosis; ANA, anti-nuclear antibody; Anti-RNAP III, anti RNA polymerase III antibody; ACA, anti-centromere antibody; ATA, anti-topoisomerase I antibody

Table 3. The prevalence of the autoantibodies in different populations.

\begin{tabular}{|c|c|c|c|c|c|c|c|}
\hline & $\begin{array}{c}\operatorname{Iran} \\
\mathrm{n}=\mathbf{4 8 1}(\%)\end{array}$ & 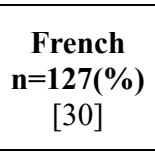 & $\begin{array}{c}\text { U.S } \\
\mathbf{n}=\mathbf{2 4 7}(\%) \\
{[30]}\end{array}$ & $\begin{array}{c}\text { Mexico } \\
\mathbf{n}=\mathbf{1 3 9}(\mathbf{\%}) \\
{[31]}\end{array}$ & $\begin{array}{c}\text { German } \\
\text { Network } \\
\mathbf{n}=\mathbf{8 6 3}(\%) \\
{[16]} \\
\end{array}$ & $\begin{array}{c}\text { Kuwana } \\
\text { Japanese } \\
\mathbf{n}=\mathbf{2 7 5}(\%) \\
{[6]} \\
\end{array}$ & $\begin{array}{c}\text { Midwesten } \\
\text { region of Brazil } \\
\mathbf{n}=46(\%) \\
{[34]} \\
\end{array}$ \\
\hline $\mathrm{dcSSc}$ & $181(37.6)$ & $24(19)$ & $116(47)$ & $60(43.1)$ & $173(20.1)$ & $71(\mathrm{NC})$ & $16(34.8)$ \\
\hline lcSSc & $300(62.4)$ & $69(54)$ & $104(42)$ & $79(56.8)$ & $513(59.4)$ & $112(\mathrm{NC})$ & $22(47.8)$ \\
\hline ANA & $434(90.2)$ & $125(98.4)$ & $245(99.2)$ & $139(100)$ & $813(94.2)$ & & \\
\hline ACA & $29(6.09)$ & $23(18)$ & $52(21)$ & $41(29.5)$ & $310(35.9)$ & $45(93)$ & $24(52.2)$ \\
\hline ATA & $348(72.3)$ & $45(35)$ & $54(22)$ & $39(28.1)$ & $260(30.1)$ & $78(66)$ & $15(32.6)$ \\
\hline Anti-RNAP III & $25(5.19)$ & $5(4)$ & $61(25)$ & $2(1.4)$ & - & & $7(15.2)$ \\
\hline
\end{tabular}

Abbreviations: lcSSc, limited cutaneous Systemic sclerosis; dcSSc, diffuse cutaneous Systemic sclerosis; ACA, anticentromere antibody; ANA, antinuclear antibody; Anti-RNAP III, anti RNA polymerase III antibody; ATA, anti-topoisomerase I antibody; NC, not calculated

According to the specific autoantibody profile, 25 patients were anti-RNAP III-positive (5.19\%), 29 were positive for ACA $(6.02 \%)$, and 348 were positive for ATA (72.3\%) (Table 3).

Among all patients, anti-RNAP III was present in 5 $(2.8 \%)$ and $20(6.7 \%) \quad \mathrm{cSSc}$ and dcSSc patients, respectively, without any significant difference $(p$ value $=$ 0.077).

The presence of ACA was found in $16(8.8 \%)$ and 13 $(4.3 \%)$ individuals with $1 \mathrm{cSSc}$ and $\mathrm{dcSSc}$, respectively, which lost its significant correlation after adjustment with the Benjamini and Hochberg method ( $p$ value $=0.073$ ).

The presence of ATA was detected in $98(54.1 \%) \mathrm{lcSSc}$ patients and $250(83.3 \%)$ dcSSc patients. ATA was the most common autoantibody in both subtypes, and it was significantly higher in dcSSc (adjusted $p$ value $<0.001$ ).

In addition, $7(3.9 \%) \mathrm{lcSSc}$ patients and $2(0.7 \%) \mathrm{dcSSc}$ cases were seronegative, which was statistically significant with an adjusted $p$ value of 0.03 . 


\section{Discussion}

Systemic sclerosis is a highly heterogeneous disorder with connective tissue involvement and an autoimmune nature, clinically characterized by the triad of endothelial dysfunction, inflammation and autoimmunity, and tissue fibrosis [25]. The importance of the study of autoantibodies lies in the fact that some of them are involved in the disease pathogenesis. Therefore, laboratory examinations to detect systemic sclerosis-relevant autoantibodies (e.g., ANA, ATA, anti-RNAP III, and ACA) provide an effective tool for the diagnosis of systemic sclerosis and the classification of disease subsets [26]. It has been estimated that over $95 \%$ of patients with systemic sclerosis have a positive ANA test, and over $85 \%$ have one or more serum autoantibodies [27]. DNA topoisomerase I (topo I), centromere proteins, RNA polymerases I, II, and III are antigens defined as intracellular targets for ANAs [28].

Systemic sclerosis is more common in women than men; however, the course of the disease may be more progressive in men [29]. Similar to other populations, i.e. U.S and French [30], Mexican [31], German Network [16], EULAR $^{1}$ Scleroderma Trials And Research (EUSTAR) group [13], and the mid-western region of Brazil [32], patients in the current study were mostly female.

In this study, it was found that $434(90.2 \%)$ patients were ANA positive and $47(9.7 \%)$ were ANA negative. Similarly, other studies have reported a high percentage of ANA [3, 16, 30, 31, 33].

ACA is directed against centromere proteins, and it has been detected in $20-25 \%$ of SSc populations that are strongly correlated with lcSSc [27]. The frequency of ACA in different studies varies from 4-52.2\% [16, 30-34], although in a study of Japanese patients by Kuwana et al., 93\% were ACA positive [6]. In the current study, the frequency of ACA, which is more associated with $\operatorname{lcSSc}[9$, 10], was low and $6.09 \%$ were ACA positive.

Different studies on different ethnic groups have reported $13-41.2 \%$ ATA positivity $[16,30-34]$. In a study of Japanese patients by Kuwana et al., 66\% were ATA positive [6]. Based on the current findings among Iranian patients, $72.3 \%$ were ATA positive, which is correlated to $\mathrm{dcSSc}$ and poor prognosis [11].

Anti-RNAP III has $98 \%$ to $100 \%$ specificity for SSc and occurs in $16 \%-20 \%$ of patients, mainly in those with the dcSSc subtype [35]. Several researchers have reported 1.49.9\% anti-RNAP III positivity in SSc patients [30, 31, 34]. Consistent with these studies, the current results demonstrated that $5.19 \%$ of SSc patient were anti-RNAP III positive. However, two studies showed U.S and Brazil SSc patients were $25 \%$ and $15.2 \%$ anti-RNAP III positive, respectively [30, 32].
Taken together, the current data showed that antiRNAP III and ATA were higher in dcSSc patients, whereas ACA was higher in lcSSc patients. In comparison with other studies, the frequency of ATA was significantly high in Iranian patients, but ACA frequency is low. With regards to the correlation of these autoantibodies with disease prognosis, it seems that more Iranian SSc patients have a poor prognosis. However, a study has reported that survival rates in Iranian SSc patients are $93 \%$ and $83 \%$ at 5 and 10 years from diagnosis, respectively [36], which is not different from other countries [37-41].

There were several discrepancies in frequency rates of autoantibodies among different studies. These conflicting results may be attributable in part to differences in sample size, ethnic background, and geographic factors, differences in the ACR criteria, the system assay used to detect autoantibodies, and diverse statistical tests.

\section{Conclusion}

A systemic sclerosis diagnosis is mainly clinical; nevertheless, quantification and identification of autoantibodies can play important roles in diagnosis. The present study illustrated differences in the autoantibodies associated with SSc disease. In accordance with the literature, this study confirms that the clinical subtype of SSc may correlate positively with the presence of specific autoantibodies. Further research is required in order to investigate the exact role of autoantibodies in SSc patients and the cause of their dissimilar frequencies among different cohorts.

\section{Acknowledgments}

The work reported herein was supported by a grant from the Deputy of Research, Tehran University of Medical Sciences (Grant No: 92-03-41-24652).

\section{Conflict of interest}

The authors report that they have no conflicts of interest to declare.

\footnotetext{
${ }^{1}$ The European League Against Rheumatism
} 


\section{References}

1. Herrick AL, Worthington J. Genetic epidemiology: systemic sclerosis. Arthritis Res 2002; 4(3):165-68. doi: $10.1186 / \operatorname{ar} 402$.

2. Tsou P-S, Sawalha AH. Unfolding the pathogenesis of scleroderma through genomics and epigenomics. J Autoimmun 2017; 83:73-94. doi: 10.1016/j.jaut.2017.05.004.

3. Behmanesh F, Amin R, Khajedaluee M, Fritzler MJ. Autoantibody profile in systemic sclerosis. Acta Med Iran 2010; 48(1):12-20.

4. Steen VD: Autoantibodies in systemic sclerosis. Semin Arthritis Rheum 2005; 35(1)35-42. doi: 10.1016/j.semarthrit.2005.03.005.

5. Mehra S, Walker J, Patterson K, Fritzler MJ. Autoantibodies in systemic sclerosis. Autoimmun Rev 2013; 12(3):340-54. doi: 10.1016/j.autrev.2012.05.011.

6. Kuwana M, Kaburaki J, Okano Y, Tojo T, Homma M. Clinical and prognostic associations based on serum antinuclear antibodies in Japanese patients with systemic sclerosis. Arthritis Rheum 1994; 37(1):75-83. doi: 10.1002/art.1780370111.

7. Ho KT, Reveille JD. The clinical relevance of autoantibodies in scleroderma. Arthritis Res Ther 2003; 5(2):80-93. doi: 10.1186/ar628.

8. Tan EM, Rodnan GP, Garcia I, Moroi Y, Fritzler M, Peebles C. Diversity of antinuclear antibodies in progressive systemic sclerosis. Arthritis Rheum 1980; 23(6):617-25. doi: 10.1002/art.1780230602.

9. Steen VD, Powell DL, Medsger Jr TA. Clinical correlations and prognosis based on serum autoantibodies in patients with systemic sclerosis. Arthritis Rheum 1988; 31(2):196-03. doi: 10.1002/art.1780310207.

10. Arnett FC, Reveille JD, Goldstein R, Pollard KM, Leaird $\mathrm{K}$, Smith EA. et al. Autoantibodies to fibrillarin in systemic sclerosis (scleroderma). An immunogenetic, serologic, and clinical analysis. Arthritis Rheum 1996; 39(7):1151-60. doi: 10.1002/art.1780390712.

11. Graf SW, Hakendorf P, Lester S, Patterson K, Walker JG, Smith MD. et al. South Australian Scleroderma Register: autoantibodies as predictive biomarkers of phenotype and outcome. Int J Rheum Dis 2012; 15(1):102-09. doi: 10.1111/j.1756-185X.2011.01688.x.

12. Koenig M, Dieudé M, Senécal J-L. Predictive value of antinuclear autoantibodies: the lessons of the systemic sclerosis autoantibodies. Autoimmun Rev 2008; 7(8):58893. doi: 10.1016/j.autrev.2008.06.010.

13. Walker U, Tyndall A, Czirjak L, Denton C, Farge-Bancel D, Kowal-Bielecka O. et al. Clinical risk assessment of organ manifestations in systemic sclerosis: a report from the EULAR Scleroderma Trials And Research group database. Ann Rheum Dis 2007; 66(6):754-63. doi: 10.1136/ard.2006.062901.

14. Ferri C, Valentini G, Cozzi F, Sebastiani M, Michelassi C, La Montagna G. et al. Systemic sclerosis: demographic, clinical, and serologic features and survival in 1,012 Italian patients. Medicine (Baltimore) 2002; 81(2):139 53. doi: 10.1097/00005792-200203000-00004.

15. Santiago M, Baron M, Hudson M, Burlingame RW, Fritzler MJ. Antibodies to RNA polymerase III in systemic sclerosis detected by ELISA. J Rheumatol 2007; 34(7):1528-34.

16. Mierau R, Moinzadeh P, Riemekasten G, Melchers I, Meurer M, Reichenberger F. et al. Frequency of diseaseassociated and other nuclear autoantibodies in patients of the German Network for Systemic Scleroderma: correlation with characteristic clinical features. Arthritis Res Ther 2011; 13(5):R172. doi: 10.1186/ar3495.

17. Jacobsen S, Ullman S, Shen G, Wiik A, Halberg P. Influence of clinical features, serum antinuclear antibodies, and lung function on survival of patients with systemic sclerosis. J Rheumatol 2001; 28(11):2454-59.

18. D'Arpa P, Machlin PS, Ratrie H, Rothfield NF, Cleveland DW, Earnshaw WC. cDNA cloning of human DNA topoisomerase I: catalytic activity of a $67.7-\mathrm{kDa}$ carboxylterminal fragment. Proc Natl Acad Sci U S A 1988; 85(8):2543-47. doi: 10.1073/pnas.85.8.2543.

19. Kuwana M, Kaburaki J, Mimori T, Tojo T, Homma M. Autoantibody reactive with three classes of RNA polymerases in sera from patients with systemic sclerosis. J Clin Invest 1993; 91(4):1399-04. doi: 10.1172/JCI116343.

20. Cox JV, Schenk EA, Olmsted J. Human anticentromere antibodies: distribution, characterization of antigens, and effect on microtubule organization. Cell 1983; 35(1):33139. doi: 10.1016/0092-8674(83)90236-2.

21. Bernat RL, Borisy GG, Rothfield NF, Earnshaw WC. Injection of anticentromere antibodies in interphase disrupts events required for chromosome movement at mitosis. J Cell Biol 1990; 111(4):1519-33. doi: 10.1083/jcb.111.4.1519.

22. Chizzolini C, Raschi E, Rezzonico R, Testoni C, Mallone R, Gabrielli A. et al. Autoantibodies to fibroblasts induce a proadhesive and proinflammatory fibroblast phenotype in patients with systemic sclerosis. Arthritis Rheum 2002; 46(6):1602-13. doi: 10.1002/art.10361.

23. van den Hoogen F, Khanna D, Fransen J, Johnson SR, Baron M, Tyndall A. et al. 2013 classification criteria for systemic sclerosis: an American College of 
Rheumatology/European League against Rheumatism collaborative initiative. Arthritis Rheum 2013; 65(11):2737-47. doi: 10.1002/art.38098.

24. Ghosh D. Incorporating the empirical null hypothesis into the Benjamini-Hochberg procedure. Stat Appl Genet Mol Biol 2012; 11(4). doi: 10.1515/1544-6115.1735.

25. Agarwal SK. The genetics of systemic sclerosis. Discov Med 2010; 10(51):134-43.

26. Bizzaro N, Bonelli F, Tonutti E, Villalta D, Tozzoli R. Autoantibody detection in scleroderma patients. Diagnostic and analytical performances of a new coupled particle light scattering immunoassay. Clin Exp Rheumatol 2002; 20(1):45-51.

27. Domsic RT, Medsger TA. Autoantibodies and their role in scleroderma clinical care. Curr Treat Opt Rheumatol 2016; 2(3):239-51. doi.org/10.1007/s40674-016-0050-y

28. Sato S, Hamaguchi Y, Hasegawa M, Takehara K. Clinical significance of anti-topoisomerase I antibody levels determined by ELISA in systemic sclerosis. Rheumatology (Oxford) 2001; 40(10):1135-40. doi: 10.1093/rheumatology/40.10.1135.

29. Wielosz E, Majdan M, Dryglewska M, Suszek D. Comparison of clinical and serological parameters in female and male patients with systemic sclerosis. Reumatologia 2015; 53(6):315-20. doi: 10.5114/reum.2015.57637.

30. Meyer OC, Fertig N, Lucas M, Somogyi N, Medsger TA. Disease subsets, antinuclear antibody profile, and clinical features in 127 French and 247 US adult patients with systemic sclerosis. J Rheumatol 2007; 34(1):104-09.

31. Rodriguez-Reyna TS, Hinojosa-Azaola A, MartinezReyes C, Nuñez-Alvarez CA, Torrico-Lavayen R, GarcíaHernández JL. et al. Distinctive autoantibody profile in Mexican Mestizo systemic sclerosis patients. Autoimmunity 2011; 44(7):576-84. doi: 10.3109/08916934.2011.592886.

32. Coelho Horimoto AM, Costa IPd. Autoantibodies in systemic sclerosis and their clinical correlation in patients from a Midwestern region of Brazil. Rev Bras Reumatol 2015; 55(3):229-39. doi: 10.1016/j.rbr.2014.09.007.

33. Reveille JD, Fischbach M, McNearney T, Friedman AW, Aguilar MB, Lisse J. et al: Systemic sclerosis in 3 US ethnic groups: a comparison of clinical, sociodemographic, serologic, and immunogenetic determinants. Semin Arthritis Rheum 2001; 30(5):33246. doi: 10.1053/sarh.2001.20268.
34. Liaskos C, Marou E, Simopoulou T, Barmakoudi M, Efthymiou G, Scheper T. et al. Disease-related autoantibody profile in patients with systemic sclerosis. Autoimmunity 2017; 50(7):414-21. doi: 10.1080/08916934.2017.1357699.

35. Jog NR, James JA. Biomarkers in connective tissue diseases. J Allergy Clin Immunol 2017; 140(6):1473-83. doi: 10.1016/j.jaci.2017.10.003.

36. Poormoghim H, Andalib E, Jalali A, Ghaderi A, Ghorbannia A, Mojtabavi N. Survival and causes of death in systemic sclerosis patients: a single center registry report from Iran. Rheumatol Int 2016; 36(7):925-34. doi: 10.1007/s00296-016-3475-6.

37. Jacobsen S, Halberg P, Ullman S. Mortality and causes of death of 344 Danish patients with systemic sclerosis (scleroderma). Br J Rheumatol 1998; 37(7):750-55. doi: 10.1093/rheumatology/37.7.750.

38. Czirják L, Kumánovics G, Varjú C, Nagy Z, Pákozdi A, Szekanecz Z. et al. Survival and causes of death in 366 Hungarian patients with systemic sclerosis. Ann Rheum Dis 2008; 67(1):59-63. doi: 10.1136/ard.2006.066340.

39. Sampaio-Barros PD, Bortoluzzo AB, Marangoni RG, Rocha LF, Del Rio APT, Samara AM. et al. Survival, causes of death, and prognostic factors in systemic sclerosis: analysis of 947 Brazilian patients. J rheumatol 2012; 39(10):1971-78. doi: 10.3899/jrheum.111582.

40. Scussel-Lonzetti L, Joyal F, Raynauld J-P, Roussin A, Rich E, Goulet J-R. et al. Predicting mortality in systemic sclerosis: analysis of a cohort of 309 French Canadian patients with emphasis on features at diagnosis as predictive factors for survival. Medicine (Baltimore) 2002; 81(2):154-67. doi: 10.1097/00005792-20020300000005 .

41. Kim J, Park SK, Moon KW, Lee EY, Lee YJ, Song YW. et al. The prognostic factors of systemic sclerosis for survival among Koreans. Clin Rheumatol 2010; 29(3):297-02. doi: 10.1007/s10067-009-1324-7. 